\title{
Acanthosis Nigricans: relation to risk of Type 2 diabetes and cardiovascular diseases among Jamaican adolescents
}

\author{
Sheila C Barrett ${ }^{*}$, Fatma G Huffman², Paulette Johnson², Adriana Campa ${ }^{2}$, Marcia Magnus ${ }^{2}$ and Dalip Ragoobirsingh $^{3}$ \\ ${ }^{1}$ School of Family, Consumer and Nutrition Sciences, Northern Illinois University, USA \\ ${ }^{2}$ Department of Dietetics and Nutrition, Robert Stempel School of Public Health, Florida International University, Miami, FL, USA \\ ${ }^{3}$ Department of Basic Medical Sciences, University of the West Indies, Mona, Kingston, Jamaica
}

\begin{abstract}
The objectives of the study were to determine if Jamaican adolescents were at risk for type 2 diabetes (T2D) and cardiovascular diseases (CVD), and examine the relationship between the presence of Acanthosis Nigricans (AN) and the risk of developing T2D and CVD among Jamaican adolescents.

A descriptive epidemiological cross-sectional study of 276 Jamaican adolescents ages 14-19 years (15.6 \pm 1.2$)$ participated. Subjects were selected from grades $9-12$ from ten high schools on the island and included males (112) and females (164). Fasting blood glucose (FBG), total cholesterol (TC), glycated hemoglobin (A1c), blood pressure (BP), body mass index (BMI), waist circumference (WC), waist-to-hip ratio (WHR), and presence of Acanthosis Nigricans were examined. Of the eight risk factors for T2D and CVD examined, the presence of AN classified more subjects at risk than all the other risk factors. Spearman correlations of AN with the other seven risk factors were highly significant for six of these other risk factors $(P<0.05)$. High A1c was the only risk factor which did not correlate with the presence of AN $(P=0.085)$. Females had significantly higher WC $(P<0.041)$, and presence of $\mathrm{AN}(P<0.013)$, whereas, males had significantly higher FBG $(P<0.039)$. Urban subjects had significantly higher BMI $(P<0.018)$ and WC $(P<0.021)$ than rural subjects. High total cholesterol was significant for subjects with lower income $(P<0.039)$. The presence of AN classified more subjects at risk than did the other seven risk factors. Examining students for the presence of AN can be economically and easily performed within the schools. A1c classified more subjects at risk for T2D and CVD than FBG and TC, however, there was no correlation between high $\mathrm{A} 1 \mathrm{c}$ and the presence of AN. Over one third of the study subjects reported three or more risk factors for T2D and CVD which indicates early intervention measures are needed for this population.
\end{abstract}

\section{Introduction}

Type 2 diabetes (T2D) in adolescents is increasing globally and is associated with the concurrent rise in the prevalence of obesity [1]. Approximately $15-16 \%$ of children ages 6-17 years in the United States of America as well as Europe are obese with another 10-15\% at risk for obesity [2,3]. In one study, Francis et al. [4] found $21 \%$ of overweight and obesity among Jamaican adolescents, a rate higher than in the United States of America. An earlier study [5], Gaskin \& Walker found more Jamaican girls than boys, ages 10-15 years to be obese.

Childhood obesity is closely associated with insulin resistance (IR), a risk factor for T2D in early adulthood [6]. T2D might go unnoticed for years while the increased hyperglycemia damages vital organs [7]. Increased rates of T2D in adolescents are now found in the developing countries [8] and is mostly linked to obesity, sedentary lifestyle, puberty, race, ethnicity, features of insulin resistance (IR), family history of T2D, being female, and perinatal factors $[9,10]$. The Caribbean has been cited by the World Health Organization as one of the regions expected to have an increase in T2D cases by 2025 [11]. Similarly, the prevalence of cardiovascular diseases (CVD) is increasing in the lesser developed countries. Up to $17 \%$ of deaths in the developing countries were attributed to CVD in 2000 [12].

In addition to $\mathrm{T} 2 \mathrm{D}$, about $60 \%$ of overweight American children also had hypertension, hyperinsulinemia, and/or hyperlipidemia; risk factors for CVD [13]. The development of CVD usually starts in the earlier years and progresses to clinically significant lesions in young adulthood $[8,14]$. Obesity has been cited as "a risk factor for CVD, ventricular dysfunction, congestive heart failure, stroke, and cardiac arrhythmias" [15]. According to Calderon et al. [16] "Persons with body mass index (BMI) $>35 \mathrm{~kg} / \mathrm{m}^{2}$ are $2-3$ times more likely than lean persons with lower BMI (18.5-24.9 $\left.\mathrm{kg} / \mathrm{m}^{2}\right)$ to die from CVD". Therefore, detection of the early signs of T2D and CVD is needed to help in the prevention of these and other related medical conditions.

Similar to higher BMI, abdominal fat or central adiposity is closely associated with hyperinsulinemia and IR [17]. According to Ramachandran (2004), "visceral fat increases the risk of diabetes and hyperlipidemia by favoring insulin resistance." Studies on nondiabetic Indians revealed that IR was associated with subcutaneous fat. Other risk factors associated with central adiposity include glucose intolerance, hyperinsulinemia, hypertriglyceridemia, and hypertension [17]. These are also risk factors for CVD. Further support comes from Patel et al. [18] who indicated that "populations with low BMI such as

Correspondence to: Sheila C. Barrett, School of Family, Consumer, and Nutrition Sciences, Department of Dietetics and Nutrition and Hospitality Administration Northern Illinois University Wirtz Hall 1425 W. Lincoln Highway DeKalb, IL 60115, USA, Tel: 815-752-7063; Fax: 815-753-1321; E-mail: sbarrett1@niu.edu

Key words: type 2 diabetes, cardiovascular diseases, adiposity, Acanthosis nigricans, metabolic syndrome, adolescents

Received: January 22, 2016; Accepted: February 23, 2016; Published: February 26,2016 
Asians tend to have high levels of abdominal fat and are particularly prone to CVD, T2D and hypertension."

Higher post-glucose insulin levels, higher triglycerides and low HDL were found in Asian Indians [19]. Another study of Mexican Americans and Asian Indians, shows that the latter had lower BMI but had greater upper body adiposity as measured by waist-to-hip ratio (WHR), which explains the high IR among Asian Indians despite having lower BMI [20]. This association with IR, high central adiposity despite lower BMI makes it imperative to examine adolescents for other risk factors such as the presence of Acnathosis Nigricans (AN), a condition associated with IR and which can serve as early detection for T2D.

Previously misdiagnosed as "Addison's disease, “Acanthosis Nigricans (AN) is manifested by dark, raised skin in areas such as the axilla, neck, knuckles, elbows, and knees and is believed to result from hyperinsulinemia and can be easily recognized by the dark, velvety plaques of body folds seen around the neckline or in the axilla of children who have greater body weight and fat mass, higher serum insulin levels and lower insulin sensitivity" [21,22]. This condition is becoming more prevalent among obese patients and those with T2D [22]. Scott et al. [23] found that $60-90 \%$ of young people with T2D also had AN. The close relationship between AN and T2D lead the American Diabetes Association to establish AN as a formal risk factor for T2D [24].

Subjects with AN are also at risk for atherosclerotic cardiovascular diseases [25]. In general, the presence of $\mathrm{AN}$ is likely to correlate with BMI [26] and high BMI has been shown to be associated with risk for T2D and CVD in several studies [27,28]. Acanthosis Nigricans and the associated IR is common among obese minority adolescents such as Native Americans, African Americans and Hispanics [29], similar results are expected among Jamaican adolescents, many of whom are of African descent and who are already showing signs of being overweight.

The presence of AN is a marker for the risk factor of hyperinsulinemia. "Hyperinsulinemia leads to binding of insulin-like growth factor (IGF) receptors on keratinocytes and fibroblasts resulting in hyperplasia of the skin" [30]. It is believed that obesity underlies this IR. High fasting blood insulin levels confirm the presence of hyperinsulinemia. Persons with hyperinsulinemia are often able to maintain glucose homeostasis despite the presence of IR. They exhibit normal blood glucose despite the presence of T2D especially in individuals if they are over 40 years. Hyperinsulinemia with normal blood glucose is an indicator of prediabetes.

Insulin resistance, that is, resistance to insulin mediated glucose disposal, is present in T2D and has been linked to CVD in earlier studies [31-33]. Reaven [31] postulated that IR may underlie other disorders such as hypertension, dyslipidemia, (high triglyceride and low HDL levels), impaired glucose tolerance, and CVD. Previous studies have shown associations with AN, T2D and atherosclerotic cardiovascular disease, therefore control of blood glucose can help to control coronary and carotid disease [31].

Obesity causes insulin resistance which is associated with AN therefore intervention is needed to correct body weight. Of the nine types of AN, obesity-associated AN is the most common type. Research indicates that the "associated skin legions are weight dependent and regresses with weight reduction" [34]. Exercise and improved diet can help to lower insulin levels and can improve AN which is expected to reduce the risk for T2D and CVD. In one study Ice et al. [34] found that
AN is an early marker for the metabolic syndrome among pediatric patients.

According to Reinehr [1], it is difficult to diagnose T2D in adolescents because there are few symptoms such as mild polyuria and polydipsia which tend to appear around mid to late puberty. Therefore, examining adolescents for the presence of $\mathrm{AN}$; a marker of IR and a marker for pediatric diabetes [34] can be performed prior to later symptoms and can be easily accomplished within the schools. The Center for Disease Control (CDC) in the United States of America recommend early screening for children over 10 years who present with any clinical signs of METS (central obesity, raised blood pressure, raised triglycerides, low HDL-C, and fasting hyperglycemia), family history of T2D, are of particular ethnic origins (Asians, Hispanics, Indians and African Americans), and if they are extremely obese with BMI of $>30 \mathrm{~kg} / \mathrm{m}^{2}$ and fall in the $>95^{\text {th }}$ percentile $[1,35]$. However, there is no known mandate for screening Jamaican adolescents for any of these conditions.

The objectives of the present study were to 1) determine if Jamaican adolescents were at risk for T2D and CVD, and 2) examine the relationship between the presence of $\mathrm{AN}$ and the risk of developing T2D and CVD among Jamaican adolescents. The authors screened for overweight and obesity and other factors that may increase the risk of T2D and CVD among Jamaican adolescents; high body mass index (BMI), waist circumference (WC), waist-to-hip ratio (WHR), fasting blood glucose (FBG), A1c, total cholesterol (TC), blood pressure (BP), and presence of Acanthosis Nigricans (AN). Demographic data; age, gender, ethnicity and place of residence were determined in relation to the above mentioned risk factors for T2D and CVD.

\section{Materials and methods}

\section{Study design}

A cross-sectional survey of 300 Jamaican adolescents ages $14-19$ years from grades 9-12 from ten Jamaican high schools, was conducted in 2007. A sample size of 300 was considered sufficient to yield 99 percent power using an F-test with a significance level of 0.05 [36]. To obtain 300 study subjects, ten schools were selected from 5 of the 14 parishes on the island. Schools within each parish were ranked as traditional (schools which offer more academic subjects and typically cater to the middle and upper class families).and non-traditional (schools which offer a vocational orientation) to obtain a representative sample of socio-economic status (SES). Two schools per parish were selected by drawing the names from a "hat." Subjects were further stratified by grade levels and gender and 30 students per school were randomly selected making a total of 300 .

Of the 300 students who were recruited, complete analyses were performed on 276. Of the 24 non-participants, 4 did not return the parental consent forms, 17 were absent due to the incessant rain experienced during the period of data collection (students were unavoidably absent), and 3 were removed from the data set due to incomplete data. The research was conducted over a period of three weeks with one school per day being targeted. Only the students whose parents gave consent and who themselves signed the assent form were included in the study. Subjects were excluded from the study if they were on medications known to alter blood pressure, glucose or lipid metabolism, and if they had known eating disorders. The study was approved by Florida International University, the Division of Standards and Regulations Ministry of Health and Environmental Control, and the Ministry of Education, Youth, and Culture, Jamaica. 


\section{Procedure}

Written permission was obtained from the principal of each school and a contact person (CP) in each school was then recruited. The CPs helped to organize students on data collection days. Contact persons included eight school nurses and two guidance counselors. Parental written consent and students' assent were then obtained. Location of assessment was based on availability of un-used space at the time of data collection and mostly took place in the "sick-bay" managed by the school nurse. Students reported for the assessment at 7:30 a.m. in each school. Students' fasting status was determined on arrival after which weights, heights, WC, and BP were taken. Students then had their blood tested by finger prick for FBG, TC and Alc. After completion of all anthropometric measures and blood tests, students were served a light breakfast to prevent hypoglycemic episodes. They returned to the researcher who examined them for physical signs of AN. Subjects completed the demographic questionnaire on their own and returned them to the researcher. Upon completion of all measures, they were given a small stipend for their participation. Assessment was completed within less than three hours each day for each school. All data were collected in October, 2007.

Students were weighed using the Professional Medical Beam Balance scale by Health-O-Meter, model 402EXP with weight capacity of $220 \mathrm{~kg}$. Weight was recorded to the nearest $0.1 \mathrm{~kg}$. Subjects were measured in their school uniforms and were asked to remove their shoes before weighing. The scale was disinfected and recalibrated after each use and the process repeated.

Height was taken using a stadiometer and recorded in centimeters and was measured to the nearest $0.5 \mathrm{~cm}$. BMI was calculated as weight $(\mathrm{kg})$ divided by height $\left(\mathrm{m}^{2}\right)$. The IOTF's proposal of a BMI above the $85^{\text {th }}$ percentile and a BMI $>$ the $95^{\text {th }}$ percentile according to Dietz and Bellizzi [37] was used to determine overweight and obesity respectively.

Blood pressure was measured using a sphygmomanometer after students were allowed to rest for five minutes. An average of two readings was used in the analysis. The height percentile, age and sex were used to ascertain the $90^{\text {th }}$ and $95^{\text {th }}$ percentiles for BP. For 17-19 year olds, adult values of $140 / 90 \mathrm{~mm} \mathrm{Hg}$ were used which is similar to the $95^{\text {th }}$ percentile.

Waist circumference and hip measurements were taken by using a non-stretchable tape using standard procedures [38]. Measurements were recorded to the nearest $0.1 \mathrm{~cm}$. Measurements of $\mathrm{WC}<94 \mathrm{~cm}$ and $<80$ represented normal, whereas $\mathrm{WC} \geq 94 \mathrm{~cm}$ and $\geq 80 \mathrm{~cm}$ represented at risk for T2D and CVD for adult males and females. Waist-to-hip ratio was calculated by dividing the WC by the hip circumference. A healthy WHR for female is 0.8 and below and for males 1.0 or below [39]. Research indicates that people with more weight around the waist face more health risks than those who carry the weight around the hip [39]. Waist to hip ratio was coded as healthy WHR $<0.8$ for females, and $<1.0$ for males and $>0.85$ for females and $>1.0$ for males for increased risk of CVD.

\section{Assessing Acanthosis Nigricans (AN)}

Examination of AN was significant to the study since AN is becoming more prevalent among obese patients and those with T2D [22]. Subjects with AN are also considered at risk for atherosclerotic cardiovascular diseases [25]. In the present study, a quantitative scale developed by Burke et al., [22] which measured the severity as well as locations for AN was used. The scale includes six AN measures; neck, axilla, neck texture, knuckles, elbows and knees to determine the presence or absence of AN as well as the severity and was found to have high inter-observer reliability $(\mathrm{k}>.68)$ and correlated well with IR and BMI among Mexican Americans. However, it was uncomfortable for the subjects to measure AN on the axilla in the current study. A quantitative scale ranging from $0-4$ was used to determine the severity of $\mathrm{AN}$ on the neck wherein $0=$ absent, $1=$ present, $2=$ mild, $3=$ moderate and $4=$ severe. For the neck texture a scale of $0-3$ wherein $0=$ smooth to the touch, $1=$ rough to touch, $2=$ coarse with raised skin, and $3=$ extremely coarse and clearly visible was used. For the knuckles, elbows and knees, a qualitative scale using the terms "present or absent" was used. In addition to the scale by Burke et al., pictures representing grades of $\mathrm{AN}$ on the neck area, and on the elbow, knuckles and axilla were also used. For the statistical analyses, presence of AN only on the neck was used and coded as present $=1$, and absent $=0$.

\section{Blood testing}

Blood testing was carried out by workers of the Mobile Unit of the Heart Foundation of Jamaica, and workers of the Diabetes Association of Jamaica. Analyses of blood for FBG, and TC were done by two workers of the Heart Foundation of Jamaica using the finger prick method. Students were pricked a second time by a worker from the Diabetes Association of Jamaica who conducted the finger prick tests for A1c only, on all study subjects.

Finger prick FBG was measured by the Accu Chek Advantage Blood Glucose Monitor (Roche Diagnostics of New Zealand). Accuracy and precision of this instrument was tested in other studies $[40,41]$. Successive drops of blood were taken for measuring TC at that moment. Test time for the FBG was about 15 seconds and results were available immediately. The results were entered on the data sheet immediately. Fasting blood glucose (FBG) was classified based on the most current ADA criteria [42] where FBG $<100 \mathrm{mg} / \mathrm{dL}$ represented normal blood glucose levels $\mathrm{FBG} \geq 100 \mathrm{mg} / \mathrm{dL}$ and $<126 \mathrm{mg} / \mathrm{dl}$ ) Impaired fasting glucose (IFG) and blood glucose $\geq 126 \mathrm{mg} / \mathrm{dLl}$ suggested diabetes.

Total cholesterol was measured using the Accutrend GCT Cholesterol Monitor (Roche, Diagnostics, Mannheim, Germany). Results were available in three minutes and used only one drop of blood for testing and was coded as; Normal (TC $<170 \mathrm{mg} / \mathrm{dL})$, Borderline (TC $170-200 \mathrm{mg} / \mathrm{dL}$ ), and Abnormal (TC $>200 \mathrm{mg} / \mathrm{dL}$ ) using the current NCEP guidelines for children. Alc was measured using the Nycocard manufactured by Axis-Shield. The Ncyocard is Diabetes Control and Complications Trial (DCCT) calibrated. The instrument used 5 microliters of blood drawn from the fingertip and is ideal for use with children and adolescents. The results were available within four minutes and measures were reported as one standardized Alc value. In this study the International Diabetes Federation guidelines of $<6.5 \%$ was used as the cut-off point for normal levels of A1c.

\section{Pilot testing of instruments}

Instrument for measuring $\mathrm{AN}$ has been used and reliability determined in a previous study [22]. The demographic questionnaire was developed by the researcher and was tested and validated among a similar sample of 40 students from a high school not included in the study.

\section{Statistics}

Statistical analyses were performed using IBM SPSS version 21 for Windows (Released 2012, Armonk, NY: IBM Corp.). Chi square analyses were performed to determine the proportion of subjects with known risk factors of T2D and CVD. Spearman Correlations 
were performed between $\mathrm{AN}$ and the other risk factors for T2D and CVD; FBG, TC, A1c. BP, BMI, WC, and WHR. Correlations were also performed between the risk factors and the demographic variables for ethnicity (Blacks and non-Blacks), gender (male, female), place of residence (rural/urban), and income (high, low). Descriptive statistics such as means, standard deviations, frequencies and percentages for demographic characteristics of the population were determined. Statistical significance was set at the 0.05 level.

\section{Results}

The study examined Jamaican adolescents for the presence of Acanthosis Nigricans and its relationship to other risk factors of T2D and CVD. A total of eight risk factors were examined; Body Mass Index (BMI), waist circumference (WC), waist-to-hip ratio (WHR), fasting blood glucose (FBG), total cholesterol (TC), glycated hemoglobin (A1c), blood pressure (BP), and the presence of Acanthosis Nigricans (AN). Variables such as gender (male, female), ethnicity, (Blacks, nonBlacks), place of residence (rural, urban), and income levels (low, high) were examined to determine how each related to the risk factors of T2D and CVD in Jamaican adolescents.

Of the 276 subjects more females (59.4\%) than males (40.6\%) participated. Participation was slightly higher in the urban than rural schools (50.7\% vs. 49.3\%). The difference in participation from the rural schools may be accounted for by the heavy rains which prevented rural children from attending school on the day of data collection with many roads being impassable. Age ranged from 14-19 years with a mean of $15.6 \pm 1.2$ years. The majority of students $(37.7 \%)$ were from grade eleven. More Blacks (77.9\%) than non-Blacks (17.0\%) participated. Table 1 shows the demographic breakdown of the sample.

\section{Assessment of Adolescents' risk for T2D and CVD}

Table 1 shows frequencies, means, and standard deviations for the risk factors of T2D and CVD. The overall mean BMI of the sample was $23.8 \pm 7.7$. Despite the high BMI levels found it must be noted that $24.6 \%$ of the sample was underweight. High WC classified $28.6 \%$ of the sample at risk for CVD or T2D. The majority of the sample $(n=255$, 92.3\%) was classified as having healthy WHR.

Data on FBG, TC and A1c reported in Table 1 were taken by finger prick measures of capillary whole blood. The total number of subjects classified at risk for T2D because of high FBG was $n=42(15.2 \%)$. The majority of the sample $(n=250,90.6 \%)$ was classified as having normal
TC levels with TC less than $170 \mathrm{mg} / \mathrm{dL}$ according to the National Cholesterol Education Program (NCEP) guidelines for children. For statistical analyses, subjects considered at risk for high TC included those with borderline as well as high levels of TC making a total of $\mathrm{n}=26(9.4 \%)$. The majority of the sample $(\mathrm{n}=202,73.2 \%)$ were classified as having normal levels $(\leq 6.5 \%)$ of Alc.

Mean systolic and diastolic BP were $116.8 \pm 16.2$ and $69.9 \pm 10.9$ $\mathrm{mmHg}$ respectively. The majority of the sample $(\mathrm{n}=205,74.3 \%)$ was classified as having normal BP which placed them in the $<90^{\text {th }}$ percentile group according to their age, gender, and height percentile with measures of systolic and diastolic blood pressure. Twenty-four (8.7\%) subjects were classified as pre-hypertensive (between the $90^{\text {th }}$ and $95^{\text {th }}$ percentile), and $n=47(17.0 \%)$ were classified as hypertensive (above the $95^{\text {th }}$ percentile). For statistical analyses subjects who classified in the 90-95 ${ }^{\text {th }}$ and above the $95^{\text {th }}$ percentile were classified at risk for high BP $(\mathrm{n}=71,25.7 \%)$.

\section{Presence of Acanthosis Nigricans (AN)}

To determine the presence of AN, students' neck, knuckles, elbows and knees were examined by the researcher using the instrument developed by Burke et al. [22]. In this study, presence of AN on the axilla was not evaluated. Grading of AN was done using pictures which represented the severity of the physical signs on the neck along with the scale developed by Burke et al. Acanthosis Nigricans is easily recognized by lines of pigmentation on the neck. For statistical purposes presence of AN was determined with the neck measures only (Table 2). Acanthosis Nigricans on the neck was graded from 1-4 ranging in severity with grade 1 representing a thin visible line on the neck; grade $2=1-2 \mathrm{~cm}$, grade $3=2-3 \mathrm{~cm}$, and grade four $>3 \mathrm{~cm}$ in width as stipulated by the Acanthosis Nigricans: The Education and Screening Program ANTES. A total of $122(44.2 \%)$ of the adolescents had physical signs of AN as observed on the neck region (Table 2).

Relationship between Acanthosis Nigricans and risk factors for T2D and CVD

Of the seven risk factors for T2D and CVD which were compared with subjects with or without AN, six risk factors were significantly correlated $(P<0.01)$ with the presence of AN. Alc was the only risk factor which did not correlate with the presence or absence of AN $(P=0.085)$ (Table 3) (Figure 1).

Comparison of risk factors with demographic and environmental variables

Table 1. Distribution of variables for risk of Type 2 diabetes and cardiovascular diseases $(\mathrm{N}=276)$

\begin{tabular}{|c|c|c|c|c|c|c|c|}
\hline Variables & $\mathbf{N}$ & $\%$ & Mean \pm SD & Variables & $\mathbf{N}$ & $\%$ & Mean \pm SD \\
\hline $\begin{array}{l}\text { Gender } \\
\text { Male } \\
\text { Female }\end{array}$ & $\begin{array}{l}112 \\
164\end{array}$ & $\begin{array}{l}40.6 \\
59.4\end{array}$ & & $\begin{array}{l}\text { Blood Pressure } \\
\text { Systolic } \\
\text { Diastolic } \\
\text { Normal }\left(<90^{\text {th }} \text { Percentile }\right) \\
\text { Pre-hypertensive }\left(90^{\text {th }}-95^{\text {th }} \text { Percentile }\right) \\
\text { Hypertensive }\left(>95^{\text {th }} \text { Percentile }\right)\end{array}$ & $\begin{array}{l}205 \\
24 \\
47\end{array}$ & $\begin{array}{c}74.3 \\
8.7 \\
17.0\end{array}$ & $\begin{array}{r}116.8 \pm 16.23 \\
69.9 \pm 10.90\end{array}$ \\
\hline $\begin{array}{l}\text { Ethnicity } \\
\text { Blacks } \\
\text { Non-Blacks }\end{array}$ & $\begin{array}{c}215 \\
61\end{array}$ & $\begin{array}{l}77.9 \\
22.1\end{array}$ & & $\begin{array}{l}\text { Fasting Blood Glucose } \\
\text { Normal }(\leq 100 \mathrm{mg} / \mathrm{dL}) \\
\text { IFG }(100-126 \mathrm{mg} / \mathrm{dL}) \\
\text { Diabetes }(\geq 126 \mathrm{mg} / \mathrm{dL})\end{array}$ & $\begin{array}{c}234 \\
39 \\
3\end{array}$ & $\begin{array}{c}84.8 \\
14.1 \\
1.1\end{array}$ & $91.21 \pm 10.53$ \\
\hline $\begin{array}{l}\text { Place of Residence } \\
\text { Rural } \\
\text { Urban }\end{array}$ & $\begin{array}{l}140 \\
136\end{array}$ & $\begin{array}{l}50.7 \\
49.3\end{array}$ & & $\begin{array}{l}\text { Total Cholesterol } \\
\text { Normal }(\leq 170 \mathrm{mg} / \mathrm{dL}) \\
\text { Borderline }(170-200) \\
\text { Above normal }(\geq 200)\end{array}$ & $\begin{array}{c}250 \\
23 \\
3\end{array}$ & $\begin{array}{c}90.6 \\
8.3 \\
1.1\end{array}$ & $143.0 \pm 21.32$ \\
\hline $\begin{array}{l}\text { Age (years) } \\
14-16 \\
17-19\end{array}$ & $\begin{array}{c}214 \\
62\end{array}$ & $\begin{array}{c}77.5 \\
222.5\end{array}$ & $\begin{aligned} 15.6 & \pm 1.2 \\
15.1 & \pm 0.8 \\
17.3 & \pm 0.5\end{aligned}$ & $\begin{array}{l}\text { A1c } \\
\quad \text { Normal }(\leq 6.5) \\
\quad \text { Above normal }(>6.5)\end{array}$ & $\begin{array}{c}202 \\
74\end{array}$ & $\begin{array}{l}73.2 \\
26.8\end{array}$ & $6.09 \pm 1.33$ \\
\hline
\end{tabular}


Table 2. Presence and severity of Acanthosis Nigricans (AN).

\begin{tabular}{|l|l|c|c|}
\hline Presence of AN & Scale & $\mathbf{N = 2 7 6}$ & $\%$ \\
\hline Neck & Present & 122 & 44.2 \\
\hline \multirow{2}{*}{ Knuckles } & Absent & 154 & 55.8 \\
\hline Elbows & Present & 47 & 17.0 \\
\cline { 2 - 4 } & Absent & 229 & 83.0 \\
\hline Neck Texture & Present & 41 & 14.9 \\
\hline & Absent & 235 & 85.1 \\
\hline \multirow{3}{*}{ 1 smooth } & 50 & 41.0 \\
\hline & 2 rough & 30 & 24.6 \\
\hline & 3 coarse & 35 & 28.7 \\
\cline { 2 - 4 } & 4 extremely coarse & 7 & 5.7 \\
\hline
\end{tabular}

\begin{tabular}{|l|c|c|c|c|c|}
\hline Variables & $\begin{array}{l}\text { Absence } \\
\text { of AN n }\end{array}$ & $\begin{array}{c}\text { Presence } \\
\text { of AN n }\end{array}$ & OR & $\chi \mathbf{2}$ & $\boldsymbol{P}$ value \\
\hline Fasting Blood Glucose $(>100 \mathrm{mg} / \mathrm{dL})$ & 15 & 27 & 8.081 & 0.171 & $0.004^{* *}$ \\
\hline Total Cholesterol $(>170 \mathrm{mg} / \mathrm{dL})$ & 9 & 17 & 5.211 & 0.138 & $0.022^{*}$ \\
\hline A1c $(>6.5 \%)$ & 35 & 39 & 2.948 & 0.104 & 0.085 \\
\hline Blood Pressure $\left(>90^{\text {th }}\right.$ Percentile $)$ & 22 & 49 & 24.035 & 0.294 & $0.000^{* * *}$ \\
\hline Body Mass Index $\left(>85^{\text {th }}\right.$ Percentile $)$ & 10 & 81 & 120.162 & 0.633 & $0.000^{* * *}$ \\
\hline $\begin{array}{l}\text { Waist Circumference }(\geq 94 \mathrm{~cm} \text { male, } \\
\geq 80 \text { cm female })\end{array}$ & 5 & 77 & 131.084 & 0.651 & $0.000^{* * *}$ \\
\hline $\begin{array}{l}\text { Waist-to-hip Ratio }(\geq 1 \text { male, } \geq .85 \\
\text { female })\end{array}$ & 4 & 17 & 12.926 & 0.212 & $0.000^{* * *}$ \\
\hline$* \mathrm{p}<0.05$ & & & & & \\
\hline
\end{tabular}

Table 3. Relationship between Acanthosis Nigricans and Risk Factors for Type 2 Diabetes and Cardiovascular Diseases $(\mathrm{N}=276)$.

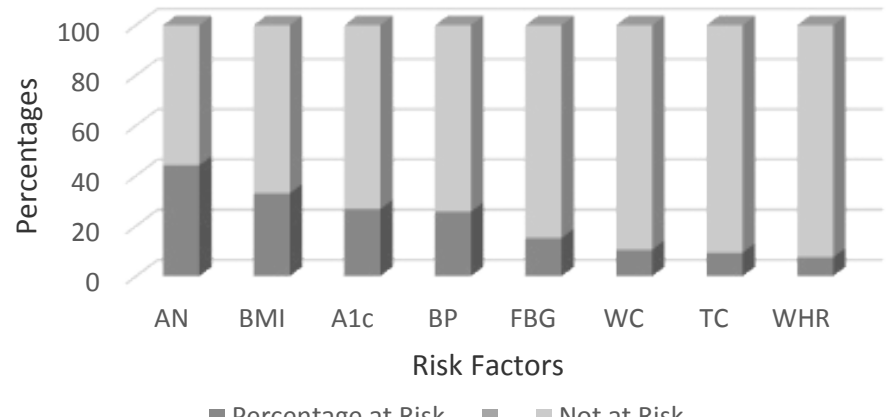

Figure 1. Comparsion of risk versus no risk for Type 2 diabetes and cardiovascular diseases. The percentage of subjects at risk for T2D and CVD. The presence of AN on the neck classified more subjects are at risk for T2D and CVD than did any of the other seven risk factors that were examined in this study followed by high BMI and high Alc. The presence of AN was then correlated with these risk factors.

Logistic regression analyses showed significance for three of the four demographic and environmental variables and selected risk factors at the 0.05 level of significance (Table 4 ) (Figure 2). Gender predicted FBG $(P=0.040)$, WC $(P=0.041)$, AN $(P=0.013)$. More males $(n=23)$ than females $(n=19)$ had high FBG, whereas a significantly higher number of females were at risk to T2D and CVD as indicated by high WC, and presence of AN. Place of residence significantly predicted BMI $(P=0.018)$, and WC $(P=0.021)$. Urban subjects had higher BMI and WC when compared to their rural counterparts Household income was significant for predicting TC $(P=0.039)$ with a significantly higher number of subjects with high TC among the lower SES group.

\section{Discussion}

The current study primarily screened Jamaican adolescents for risk of T2D and CVD. Screening for risk factors of T2D and CVD is important for children over 10 years, especially if they are overweight and belong to ethnic groups at risk, among other factors $[1,35]$. The economic burden for treating the comorbidities resulting from overweight and obesity is especially important for developing countries such as Jamaica. Associated with overweight and obesity are high BP, WC, WHR, and FBG which are features of the metabolic syndrome, as well as hyperinsulinemia among other conditions. Research on the metabolic syndrome among Jamaican adults by Ferguson et al. [43] indicates the need for screening Jamaican children and adolescents as increasing number of adults are already experiencing these symptoms. Early prevention may prevent, ameliorate or delay these symptoms.

The majority of the subjects reported more than three risk factors which place them at risk for the metabolic syndrome. The number of risk factors reported and prevalence of the metabolic syndrome among this study population have been published elsewhere [44]. Of the eight risk factors examined in this study, the presence of $\mathrm{AN}$, high $\mathrm{BMI}$ and WC were the strongest predictors of T2D and CVD. Brickman et al. [45] found that the presence of AN identifies youth at high risk for the metabolic syndrome. Over one-third of the current population was overweight and obese. As noted in another study by Ice et al. [34], obesity-associated AN is a reliable and early marker for the metabolic syndrome in pediatric patients. High prevalence of overweight was found among the current study subjects. Despite the high prevalence of overweight, almost a quarter of the current population was also underweight. This was not surprising as this mirrors the obesity paradox where both overweight and underweight are found in the same populations [46].

Having established that Jamaican adolescents are at risk for T2D and CVD, we examined the relation between $\mathrm{AN}$ and these risk factors. AN was associated with high BMI [34], ethnic origins [47,48] and also insulin resistance in other studies [49]. Stoddart et al., [47], and Pattamadilok et al., [48] found higher prevalence of AN among individuals with darker skin pigmentation with African Americans having a prevalence of $13.3 \%$. This high prevalence was also expected in our study with a majority of the participants being of African descendants. When BMI and ethnicity were combined, other studies [50-52], found that children of any race had a $62 \%$ prevalence of AN if their BMI is greater than the $98^{\text {th }}$ percentile. Higgins [49] postulate that "the association of AN with IR may be due to high concentrations of insulin producing a potent proliferative effects by binding to

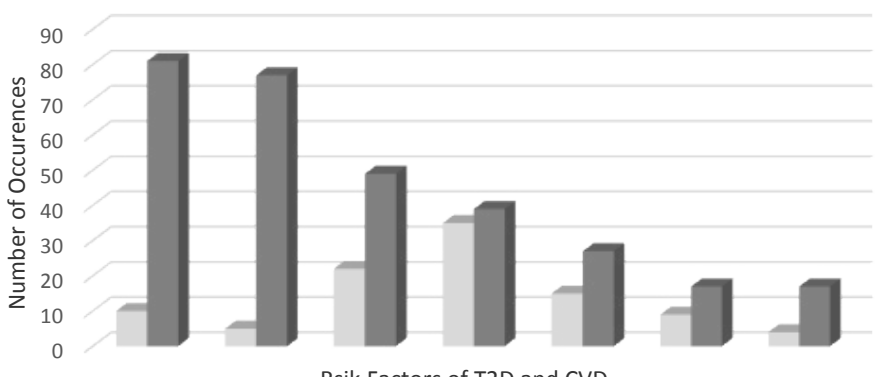

Rsik Factors of T2D and CVD

Absence of AN $\square$ Presence of AN

Figure 2. Comparsion of risk factors of Type 2 diabetes and cardiovascular diseases acanthosis Nigricans. Comparison of subjects with and without AN on the neck, with each of the risk factors for T2D and CVD. In all cases, subjects were at risk for high BMI, WC, BP, A1c, FBG, TC and WHR whether they had AN or not. The presence of AN was higher for those subjects with high BMI, high WC and high BP. Therefore, screening for AN can help to identify other potential risk factors for T2D and CVD. 
Table 4. Relationships among Gender Ethnicity, Place of Residence, Income and Risk Factors of Type 2 Diabetes and Cardiovascular Diseases (N=276).

\begin{tabular}{|c|c|c|c|c|c|c|c|c|c|c|c|c|c|}
\hline \multirow[t]{2}{*}{$\begin{array}{l}\text { Risk } \\
\text { Factors }\end{array}$} & \multirow[t]{2}{*}{$\begin{array}{l}\text { Model } \\
P \text { value }\end{array}$} & \multicolumn{3}{|c|}{$\begin{array}{c}\text { Gender } \\
\text { (Male) }\end{array}$} & \multicolumn{3}{|c|}{$\begin{array}{c}\text { Ethnicity } \\
\text { (Non-Black) }\end{array}$} & \multicolumn{3}{|c|}{$\begin{array}{c}\text { Place of Residence } \\
\text { (Urban) }\end{array}$} & \multicolumn{3}{|c|}{$\begin{array}{c}\text { Household Income } \\
\text { (Low) }\end{array}$} \\
\hline & & OR & $95 \%$ CI & $P$ value & OR & $95 \%$ CI & $P$ value & OR & $95 \% \mathrm{CI}$ & $P$ & OR & $95 \%$ CI & $\begin{array}{c}P \\
\text { value }\end{array}$ \\
\hline High FBG & .332 & 2.01 & $1.03-3.93$ & .040 & 0.86 & $0.37-2.00$ & .729 & 0.81 & $0.42-1.6$ & .555 & 0.92 & $0.53-2.21$ & .829 \\
\hline High TC & .036 & 0.61 & $0.25-1.50$ & .281 & 0.36 & $0.07-1.45$ & .141 & 1.20 & $0.52-2.78$ & .674 & 3.70 & $1.06-12.8$ & .039 \\
\hline High BMI & .100 & 0.64 & $0.37-1.09$ & .101 & 1.03 & $0.55-1.93$ & .917 & 1.87 & $1.1-3.14$ & .018 & 1.03 & $0.58-1.76$ & .955 \\
\hline High WC & .043 & 0.56 & $0.32-0.97$ & .041 & 0.88 & $0.46-1.69$ & .708 & 1.90 & $1.1-3.2$ & .021 & 0.79 & $0.45-1.37$ & .398 \\
\hline Presence of AN & .080 & 0.53 & $0.32-0.87$ & .013 & 0.66 & $0.36-1.21$ & .175 & 0.88 & $0.54-1.44$ & .618 & 0.04 & $0.56-1.59$ & .817 \\
\hline
\end{tabular}

Note: Bold represent statistical significance at $\mathrm{p}<0.05$ level

the insulin- like growth factor -1 (IGF-1) receptors." Further, "free IGF-1 levels may be higher in obese subjects with hyperinsulinemia, these higher levels of free IGF-1 leads to increased cell growth and proliferation" [49].

Insulin resistance is a warning sign for T2D, however, IR could not be measured by the finger prick blood samples used in the current study. Despite the absence of IR in our study, we found strong evidence that links AN to the other risk factors of T2D and CVD. In our study AN positively and significantly correlated with high BMI, WC, BP, FBG, TC, and WHR. However, no correlation was found between AN and Alc. An almost equal number of subjects (35 versus 39 ) had high A1c whether or not they had any physical signs of AN on the neck. In a previous study by Barrett et al. [53], it was found that finger prick testing of Alc classified more subjects at risk when compared with venous testing. The current study used finger prick measures of Alc which might account for the prevalence of high A1c among this population.

Our findings are similar to earlier research by Burke et al. [22] and Scott $e$ t al. [23] who found that $60-90 \%$ of young people with T2D also had AN. Further, Katz and Feldman, [25] also reported that subjects with AN were also at risk for atherosclerotic cardiovascular diseases. Our findings on high BMI, risk for T2D and CVD and the presence of AN are supported by other studies [26-28]. Hirschler et al. [26] found that the presence of AN is likely to correlate with BMI. Whereas, Kong et al. [27] and Nguyen et al. [28] found that high BMI has been shown to be associated with risk for T2D and CVD. Therefore, a screening method that can easily identify risk of T2D such as examining the neck of adolescents for physical signs of AN, which is not invasive or costly, can serve as a warning and prevention strategy for T2D.

We found evidence of high FBG among males, whereas females had higher WC, and presence of AN. As noted in other studies by Scott et al. [54] and Brickman et al. [45], "children with AN have higher levels of basal glucose-stimulated insulin compared with obese children without AN." Further, AN is present with hyperinsulinemia, and is independent of BMI. We found no significant difference in BMI for males and females in our study. However, subjects living in urban areas had higher BMI than their rural counterparts. Urban subjects also had higher WC. Surprisingly high total cholesterol was found among the lower socio economic status (SES) group. This is contrary to our expectations considering that animal foods which are the sources of cholesterol are more expensive. We expected a higher prevalence of AN and the other risk factors for T2D and CVD among Blacks, however, ethnicity was not significant for any of the risk factors examined considering that the study population was predominantly Black.

Examination of adolescents for signs of AN as a risk factor for T2D and CVD was a novel piece to this research study. The study subjects were not aware of what this line around their necks represented. Subjects were surprised that this line is indicative of developing T2D in later years and expressed a desire to begin to lose weight to help reverse this condition. Along with the minimal cost of assessment of the neck for $\mathrm{AN}$, the cost of conducting this screening with finger-prick blood testing rather than venous sampling of blood and consequent laboratory testing made the cost manageable, and the ability to provide feedback more expedited.

Prevention of chronic diseases such as T2D and CVDs can greatly reduce healthcare costs for governments in many countries especially in the resource-poor countries, and increase quality of life. Recent reports showed that cases of diabetes have doubled in Jamaica between 1980 and 2000. Jamaica spends approximately 42 billion dollars annually on the treatment of diabetes and hypertension [55]. Limitations to the study include the inability to measure insulin resistance but many other risk factors were examined.

Similar to the research by Sacks, et al. [56], we suggest screening children over the age of 10 years for T2D, if the child is overweight and has two other risk factors (family history, race/ethnicity, and signs of insulin resistance). There is evidence that the atherosclerotic lesions associated with CVDs in later years begin in early childhood according to Gungor et al. [8] and Steinberger et al. [14]; therefore, screening of adolescents for risk factors of CVDs is also recommended. Other recommendations from our study include:

Screening school children for risk factors of T2D and CVDs biannually within the school system. This is manageable since all parties concerned gave their full support to the study. The Ministry of Health and Environmental Control and the Ministry of Education, Youth and Culture did not oppose this screening within the schools. Parents did not object to having their child tested at schools and children were quite willing to undergo testing. Principals and school nurses were supportive and did not object to this type of screening.

Sensitizing the school nurses to the growing problems of childhood obesity and the related metabolic syndrome. The school nurses can be trained to conduct these finger prick tests with the permission of the Ministry of Health and Environmental Control and the Ministry of Education, Youth, and Culture. Cost of testing can be made part of the cost-sharing efforts in the schools between parents and government subsidies.

Conduct follow-up testing and monitoring for children and adolescents who are overweight and obese, those who present with grade 3 and 4 for severity of AN on the neck, high WC, FBG, TC, A1c levels, pre-hypertension and hypertension. Training the school nurses and guidance counsellors (who can notify the parents) to recognize the physical signs for AN requires little training and no additional cost to the school or parents. Identification of these risk factors can help in the 
planning of early intervention to improve the long-term outcomes of these chronic diseases. Simple monitoring of body weight is achievable at no extra cost to the schools.

Re-introduce physical education to all grades in high schools to reduce the growing rates of overweight and obesity.

Teach students about the importance of diet for the prevention of T2D and CVDs in the nutrition classes at the high school level. It is customary for students to select specific subjects at the end of grade nine, and many might not choose food and nutrition for further studies. Therefore, nutrition knowledge on these chronic, nutritionrelated diseases is best introduced at grade nine.

Repeatability of the methods of blood testing may be carried out and have one agency conduct all tests to reduce variation among tests results. Coordination of three different agencies on data collection days was challenging therefore for future studies one agency/laboratory should be used for all blood tests. Measuring IR is recommended since other studies indicate that IR is a good indicator of the metabolic syndrome in adolescents and is a strong marker for T2D. Our study has set the framework for further studies on nutrition-related chronic diseases among Jamaican adolescents. Based on evidence from this research on the prevalence of risk factors for T2D and CVDs among Jamaican adolescents, there is need to be develop interventions to prevent risks leading to these costly and fatal chronic diseases.

\section{Conclusion}

Over a third of the study subjects were overweight or obese which places them at risk for T2D and CVD. Those who are already diagnosed with pre-diabetes should be monitored to prevent or delay further development to diabetes. Although AN did not correlate with high A1c, the high numbers of adolescents who had high Alc is a cause for concern. Of importance is controlling the disease to prevent further complications such as hypertension, hyperlipidemia, and cardiovascular diseases. Jamaican adolescents are at risk for T2D and CVDs similar to other ethnic minority groups in the US. They also tend to have a cluster of risk factors for T2D and CVDs as seen in other studies. Over $60 \%$ of the sample had three or more risk factors for T2D and CVDs despite their weight status. BMI and WC strongly predicted some of the risk factors for T2D and CVDs. One third of our sample had BMI $\geq 25$ which is twice the percentage of overweight adolescents in the United States of America. The presence of AN was found in over $40 \%$ of the sample and correlated with high BMI as seen in other study populations of adolescents. Ethnicity, gender, place of residence and income levels also predicted the risk factors of T2D and CVDs.

\section{Conflict of interest}

The authors declare no conflict of interest.

\section{References}

1. Reinehr T (2005) Clinical presentation of type 2 diabetes mellitus in children and adolescents. Int J Obes (Lond) 29: S105-110. [Crossref]

2. Theintz G (2005) From obesity to type 2 diabetes in children and adolescents. Rev Med Suisse 1: 477-480. [Crossref]

3. Ogden CL Carroll MD, Curtin LR, Lamb MM, Flegal KM (2010) Prevalence of high body mass index in US children and adolescents, 2007-2008. JAMA 303: 242-249. [Crossref]

4. Francis DK, Van den Broeck J, Younger N, McFarlane S, Rudder K, et al. (2009) Fastfood and sweetened beverage consumption: association with overweight and high waist circumference in adolescents. Public Health Nutr 12: 1106-1114. [Crossref]

5. Gaskin PS Walker SP (2003) Obesity in a cohort of black Jamaican children as estimated by BMI and other indices of adiposity. Eur J ClinNutr 57: 420-426. [Crossref]

6. Steinberger J Moran A, Hong CP, Jacobs DR Jr, Sinaiko AR (2001) Adiposity in childhood predicts obesity and insulin resistance in young adulthood. J Pediatr 138: 469-473. [Crossref]

7. McKnight-Menci H Sababu S, Kelly SD (2005) The care of children and adolescents with type 2 diabetes. J PediatrNurs 20: 96-106. [Crossref]

8. Gungor N Arslanian S (2002) Pathophysiology of type 2 diabetes mellitus in children and adolescents: treatment implications. Treat Endocrinol 1: 359-371. [Crossref]

9. Marcovecchio M Mohn A, Chiarelli F (2005) Type 2 diabetes mellitus in children and adolescents. J Endocrinol Invest 28: 853-863. [Crossref]

10. Berry D Urban A, Grey M (2006) Understanding the development and prevention of type 2 diabetes in youth (part 1). J Pediatr Health Care 20: 3-10. [Crossref]

11. World Health Organization (2003) Global strategy on diet, physical activity and health: European regional consultation. Report on the Consultation, Copenhagen.

12. Nugent R (2006) Obesity-related diseases creep up on developing countries. Population Reference Bureau.

13. Freedman DS Dietz WH, Srinivasan SR, Berenson GS (1999) The relation of overweight to cardiovascular risk factors among children and adolescents: the Bogalusa Heart Study. Pediatrics 103: 1175-1182. [Crossref]

14. Steinberger J, Daniels R (2003) Obesity, insulin resistance, diabetes, and cardiovascular risk in children. An American Heart Association scientific statement from the Atherosclerosis, Hypertension and Obesity in the Young Committee (Council on Cardiovascular Disease in the Young) and the Diabetes Committee (Council on Nutrition, Physical Activity, and Metabolism). Circulation 107: 1448-1453.

15. Klein S, Burke LE, Bray GA, Blair S, Allison DB, et al. (2004) Clinical complications of obesity with specific focus on cardiovascular disease. Circulation 2: 2952-2967.

16. Calderon KS, Yucha CB, Schaffer SD (2005) Obesity-related cardiovascular risk factors: Intervention recommendations to decrease adolescent obesity. Journal of Pediatric Nursing 20: 3-14.

17. RamachandranA (2004) Diabetes and Obesity- The Indian Triangle. Indian Journal of Medical Research. Indian Council of Medical Research.

18. Patel S Unwin N, Bhopal R, White M, Harland J, et al. (1999) A comparison of proxy measures of abdominal obesity in Chinese, European and South Asian adults. Diabet Med 16: 853-860. [Crossref]

19. McKeigue PM Shah B, Marmot MG (1991) Relation of central obesity and insulin resistance with high diabetes prevalence and cardiovascular risk in South Asians. Lancet 337: 382-386. [Crossref]

20. Ramachandran A, Snehalatha C, Viswanathan V, Viswanathan M, Haffner SM (1997) Risk of non-insulin dependent diabetes mellitus conferred by obesity and central adiposity in different ethnic groups: a comparative analysis between Asian Indians, Mexican Americans and Whites. Diabetes Research in Clinical Practice 36: 121-125.

21. Bindler RM Bruya MA (2006) Evidence for identifying children at risk for being overweight, cardiovascular disease, and type 2 diabetes in primary care. $J$ Pediatr Health Care 20: 82-87. [Crossref]

22. Burke JP Hale DE, Hazuda HP, Stern MP (1999) A quantitative scale of acanthosisnigricans. Diabetes Care 22: 1655-1659. [Crossref]

23. Scott CR, Smith JM, Cradock MM, Pihoker C (1997) Characteristics of youth-onset noninsulin-dependent diabetes mellitus and insulin-dependent diabetes mellitus at diagnosis. Pediatrics 100: 84-91. [Crossref]

24. Sinha S, Schwartz RA (2007) Juvenile acanthosisnigricans. J Am AcadDermatol 57 502-508. [Crossref]

25. Katz AS, Feldman SR (2006)AcanthosisNigricans in obese patients: Presentations and implications for prevention of atherosclerotic vascular disease. Dermatology Online Journal.

26. Hirschler V, Aranda C, Oneto A, Gonzalez C, Jadzinsky M (2002) Is acanthosisnigricans a marker of insulin resistance in obese children? Diabetes Care 25: 2353. [Crossref]

27. Kong AS, Williams RL, Smith M, Sussman AL, Skipper B, et al. (2007) Acanthosisnigricans and diabetes risk factors: prevalence in young persons seen in southwestern US primary care practices. Ann Fam Med 5: 202-208. [Crossref]

28. Nguyen TT, Keil MF, Russell DL, Pathomvanich A, Uwaifo GI, et al. (2001) Relation of acanthosisnigricans to hyperinsulinemia and insulin sensitivity in overweight African American and white children. J Pediatr 138: 474-480. [Crossref] 
29. Tajima N (2002) Type 2 diabetes in children and adolescents in Japan. International Diabetes Monitor 14: 1-5.

30. Cruz PD, Hud JA (1992) Excess insulin binding to insulin-like growth factor receptors: proposed mechanism for AcanthosisNigricans. Journal of Investigative Dermatology 98: 82S-85S.

31. Reaven GM (1988) Banting lecture 1988. Role of insulin resistance in human disease. Diabetes 37: 1595-1607. [Crossref]

32. Laakso M (1996) Insulin resistance and coronary heart disease. CurrOpinLipidol 7: 217-226. [Crossref]

33. Stern MP (1996) Do non-insulin-dependent diabetes mellitus and cardiovascular disease share common antecedents? Annals of Internal Medicine 124(1PT 2): 110-116.

34. Ice CL, Murphy E, Minor VE, Neal WA (2009) Metabolic syndrome in fifth grade children with acanthosisnigricans: results from the CARDIAC project. World J Pediatr 5: 23-30. [Crossref]

35. Singh R, Shaw J, Zimmet P (2004) Epidemiology of childhood type 2 diabetes in the developing world. Pediatr Diabetes 5: 154-168. [Crossref]

36. Faul F, Erdfelder E (1992) GPOWER: A priori, post hoc, and computer analyses for MS_DOS (Computer program). Bonn FRG: Bonn University, Dept. of Psychology. Food and Agricultural Organization of the United Nations.

37. Dietz WH, Bellizzi MC (1999) Introduction: the use of body mass index to assess obesity in children. Am J ClinNutr 70: 123S-5S. [Crossref]

38. Chan DC, Watts GF, Barrett PH, Burke V (2003) Waist circumference, waist-to-hip ratio and body mass index as predictors of adipose tissue compartments in men. $Q J M$ 96: 441-447. [Crossref]

39. Dalton M, Cameron AJ, Zimmet PZ, Shaw JE, Jolley D, et al. (2003) Waist circumference, waist-hip ratio and body mass index and their correlation with cardiovascular disease risk factors in Australian adults. J Intern Med 254: 555-563. [Crossref]

40. Cohen M, Boyle E, Delaney C, Shaw J (2006) A comparison of blood glucose meters in Australia. Diabetes Res ClinPract 71: 113-118. [Crossref]

41. Khan AI, Vasquez Y, Gray J, Frank HW Jnr (2006)The variability of results between point-of-care testing glucose meters and the central laboratory analyzer. Archives of Pathology and Laboratory Medicine 130: 1527-1532.

42. American Diabetes Association (2005) Clinical Practice Recommendations 2005. Diabetes Care 28: S1-79. [Crossref]

43. Ferguson TS, Tulloch-Reid MK, Younger NOM, Knight-Madden JM,Samms-Vaughn M, et al. (2010) Prevalence of the metabolic syndrome and its components in relation to socioeconomic status among Jamaican young adults: a cross-sectional study. $B M C$ Pub Health 10: 307.
44. Barrett SC, Huffman FG, Johnson P (2014) Physical Activity and Metabolic Syndrome among Jamaican Adolescents. J Nutr Food Sci S8.

45. Brickman WJ, Huang J, Silverman BL, Metzger BE (2010) Acanthosisnigricans identifies youth at high risk for metabolic abnormalities. J Pediatr 156: 87-92. [Crossref]

46. Kushner RF (2012) Clinical assessment and management of adult obesity. Circulation 126: 2870-2877. [Crossref]

47. Stoddart ML, Blevins KS, Lee ET, Wang W, Blackett PR, et al. (2002) Association of acanthosisnigricans with hyperinsulinemia compared with other selected risk factors for type 2 diabetes in Cherokee Indians: the Cherokee Diabetes Study. Diabetes Care 25: 1009-1014. [Crossref]

48. Pattamadilok B, Devpura S, Syed ZU, Agbai ON, Vemulapalli P, et al. (2012) Quantitative skin color measurements in acanthosisnigricans patients: colorimetry and diffuse reflectance spectroscopy.PhotodermatolPhotoimmunolPhotomed 28:213-5.

49. Higgins SP, Freemark M, Prose N (2008) Acanthosisnigricans: a practical approach to evaluation and management. Dermatol Online J 14: 2. [Crossref]

50. Brickman WJ, Binns HJ, Jovanovic BD, Kolesky S, Mancini AJ, et al. (2007) Acanthosisnigricans: a common finding in overweight youth. PediatrDermatol 24: 601-606. [Crossref]

51. Otto DE, Wang X, Tijerina SL, Reyna ME, Farooqi MI, et al. (2010) A comparison of blood pressure, body mass index, and acanthosisnigricans in school-age children. $J$ SchNurs 26: 223-229. [Crossref]

52. Voorhees J, Goto K, Wolff C (2014) Overweight, elevated blood pressure, acanthosisnigricans and adherence to recommended dietary and physical activity guidelines among Hmong and white middle school students. J Immigr Minor Health 16: 273-279. [Crossref]

53. Barrett SC, Huffman F, Johnson P (2011) Validation of Finger-prick Testing of FBG, $\mathrm{TC}$, and $\mathrm{HbAlc}$ in Adolescents. Point of Care: The Journal of Near-Patient Testing and Technology 10: 51-58.

54. Scott AT, Metzig AM, Hames RK, Schwarzenberg SJ, Dengel DR, et al. (2010) Acanthosisnigricans and oral glucose tolerance in obese children. ClinPediatr (Phila) 49: 69-71. [Crossref]

55. Pan American Health Organization (2008) PAHO representative highlights chilling effects of non-communicable diseases. Jamaica Information Service.

56. Sacks DB, Bruns DE, Goldstein DE, Maclaren NK, McDonald JM, et al. (2002) Guidelines and recommendations for laboratory analysis in the diagnosis and management of diabetes mellitus. ClinChem 48: 436-472. [Crossref]

Copyright: (C2016 Barrett SC. This is an open-access article distributed under the terms of the Creative Commons Attribution License, which permits unrestricted use, distribution, and reproduction in any medium, provided the original author and source are credited. 